\title{
On the Postcolonial Hybridity Theory in Translation Studies
}

\author{
Ying Li \\ Foreign Language School \\ Huanghe Science and Technology College \\ Zhengzhou, China
}

\begin{abstract}
Since the coming of the deconstructionism and the "cultural turn" in translation studies, many approaches of translation studies have mushroomed, the hybridity theory in the light of post-colonialist studies has attracted more and more translation scholars. Hybridity theory, aiming to deconstruct and demystify the classical canon of the Western imperial colonialism, to resist the Euro-American cultural hegemony, to diminish the West centrism, to eliminate the binary opposition, and to reconstruct the subjectivity of the Subaltern and the "minorities" or the weak culture with the aspiration to help them find their own cultural identity, offers a different space for the research of translation.
\end{abstract}

Keywords-post-colonialist studies; hybridity theory; Translation

\section{THE BRIEF INTRODUCTION OF HYBRIDITY THEORY}

According to Oxford English Dictionary, the word "hybrid" did not appear until the 17th century and was less used before the 19th century [1]. The term "hybrid" was originally used in the subject of biology, which refers to "an animal or plant produced from parents of different breeds or types" or "a person whose parents are from different races". After 19th century, the term was more and more broadly applied to the fields of natural science like biology, computer etc. and then to the fields of social science like linguistics, literary theory, and cultural studies and so on.

When studying hybridity theory, we can not avoid an important term-post-colonialism. Post-colonialism, initiated in 1970s, has become an academic trend with strong political and cultural intention. It focuses on the relationship between the suzerain and the colony. One of the characteristics of postcolonialism is that it is not a rigid theory, and that it often changes with the changing of the outside world. Postcolonialism is not a single theory, but a series of theories including literature, art, philosophy, politics, culture, sociology, religion and so on. Post-colonialism originally and primarily aims to fight against the residual effects of the cultural invasion of the colonialism and promote the mutual respects in the cultural communication, which may help the culturally inferior countries to find their own voices which might have once been silenced by the cultural hegemony. Therefore, postcolonialism studies have strong desire to dissolve the unequal power relationships between the superior and inferior cultures.
Edward Said, Gayatri Chakravorty Spivak, Frantz Fanon, Homi Bhabha are the four main representatives in this realm.

The term "hybridity" was from Homi Bhabha's famous work entitled The Location of Culture [2], in which he had made a detailed analysis about the theory of hybridity in translation. It aims to deconstruct and demystify the classical canon of the Western imperial colonialism, to resist the EuroAmerican cultural hegemony, to diminish the West centrism, to eliminate the binary opposition, and to reconstruct the subjectivity of the Subaltern and the "minorities" or the weak culture with the aspiration to help them find their own cultural identity. In recent years, with the popularity of postcolonial theory and cultural studies, some translation scholars, especially the post-colonialist scholars, move their eyes to the issue of hybridity and pay due attention to it.

\section{RESEARCH OF HYBRIDITY IN TRANSLATION STUDIES}

\section{A. Research on Hybridity in the West}

The issue of hybridity has been widely concerned in the western academic world, and then some scholars in translation studies realize its values. Hybridity in translation studies falls into two types: one is hybridity in the ST and the other is hybridity in the TT. The former refers to the multilingual text in which different lingual elements are hybridized. The latter means that a great deal of linguistic, cultural and literary heterogeneous elements are retained from the source language, culture and literature.

For the phenomenon of hybridity in the ST, translation studies mainly concern the phenomenon of the multilingual texts. First of all, many scholars notice that multilingual texts bring challenges to translators. Antonie Berman gives enough attention to the challenges of this multilingual text against translation practice. He says that it is the multilingual phenomenon that makes translation trapped in difficulties [3]; many other scholars, like Sherry Simon, Judith Woodsworth, Samia Mehrez, also consider that those hybridized postcolonial texts are great challenges for translators. Another important term in the postcolonial cultural theories is "diaspora" which has the similar meaning with hybridity. Robinson D. holds that "diaspora" is used to show the discrepancy between languages and cultures, and to reveal the otherness and the hybridity [4]. 
Scholars pay more attention to the unique features of language and culture in the translated texts, and find the hybridity in the TT. Theo Herman [5] says that the translated text can not adequately and naturally adapt to the new environment and space like the idiomatic writings by the native writers do. In other words, comparing with original works in the target literature, the translated text unavoidably entails some heterogeneous elements and is surely hybrid text. Duff [6] regards the language in the TT of English literature as "the third language", arguing that no matter how successful a translation is, it reads somewhat like being translated from a foreign language. These scholars have actually pointed out the linguistic hybridity in the translated text.

It was Christina Schaffner and Beverly Adab [7] who put forward the notion of "hybrid text". They claimed that the "hybrid text" has distinctive characteristics in the current inter-cultural communication, and that it is the unavoidable result of translation. According to Schaffner and Adab, the hybrid text refers to a text produced in the process of translation, which demonstrates some features (being abnormal or strange) for the TC. However, these features are not caused by translators' lack of translating competence, but by their deliberate purpose. They also asserted that all translations, in some degree, are hybrid texts. Specifically speaking, this kind of text has two features: one is to retain some or all the features of the SC so as to produce a new text type in the TC; the other is to reflect some specific (lexical, syntactic and stylistic) textual features which collide with norms in the TL (ibid).

Some scholars pay attention to the influence of the hybrid translated text on the TC. Lawrence Venuti discusses invisibility hand in hand with two types translating strategy: domestication and foreignization. Venuti [8] sees domestication as dominating Anglo-American translation culture. On the other hand, Venuti views foreignization as a strategy he also terms "resistance". For Venuti, the foreignizing method of translating is a non-fluent or estranging translation style designed to make visible the presence of the translator by highlighting the foreign identity of the source text and protecting it from the ideological dominance of the TC [9].

Bhabha's hybridity theory derives from Bakhtin's novelistic discourse theory, the Lacan's psycho-analysis and Derrida's deconstructionism. Combining these thoughts, Bhabha employed hybridity in translation studies in the context of post-colonialism, aiming to end the long-lasting disputation between literal translation and free translation, foreignization and domestication. Therefore, Bhabha's introduction of hybridity is taken as a great contribution to translation studies. According to Bhabha, hybridity is "a third space" which defies the binary oppositions in the theoretical research paradigms of translation studies. Tejaswini Niranjana [10] claimed that we could view hybridity as the sign of postcolonialist theory which subverted the reading model of essentialism when pointing to the new translational practice.

Some scholars also discussed the linguistic and cultural influence on the choice of translational strategies. Some scholars held that Bhabha's elaborate description had obligatory enlightenment to the translators in the first world. The implied meaning is that translators of the western cultural hegemonies should learn some lessons from the immense subversive function of cultural hybridity and then try to keep more heterogeneous elements of the original language, culture and literature, so as to dissolve the western cultural hegemonies.

\section{B. Research on Hybridity in China}

Before Han Ziman's doctoral dissertation, scholars in Chinese translation academia are not familiar with the term of hybridity, but there are some scholars who have made some initial research. In The Chinese Translation Dictionary, Li Quan'an [11] gives an analysis of the issue of hybridity in the ST and poses the term of hybridity (in Chinese “杂交”) directly. In order to dissolve the defects of dichotomies in translation studies, Zheng Hailing [12] puts forward his famous "Harmonious Theory", emphasizing the harmonious co-existence between the SL/SC and TL/TC.

Professor Yang Xiaorong, in her the Guidance to Translation Criticism [13], put forward the criterion for translation: "the third state" (it is neither A nor B, but shares both $\mathrm{A}^{\prime}$ and $\mathrm{B}$ ' main features). From the words mentioned above, it is easy to find that Yang Xiaorong's "the third state" is similar to what Bhabha named "hybridity".

In China, Han Ziman can be seen as the first person to talk about hybridity in literary translation. In the essay Hybridity and Literary Translation [1], he went on a tentative study on hybridity, and in 2005, Han Ziman finished his book Hybridity in Literary Translation [14]. In this book, he made a thorough study on the hybridity phenomenon in literary translation. Han Ziman claims that all translated texts are hybrid texts, but some translated texts have lower degrees of hybridity, and others have higher degrees of hybridity. He also argues that the degrees of hybridity are determined by the translation strategies and methods adopted by translators.

Objectively speaking, the colonialism contributes to the occurrence of hybridity, but the colonial subject sometimes tries to deny or oppress hybridity so as to ensure the purity and originality of its authority, and so hybridity is also a kind of power to resist or subvert the colonial cultural hegemonies. The hybrid translated texts can dissolve the long-lasting binary opposition between colonies and their suzerains or between the inferior culture and the superior culture, demonstrating the heterogeneous elements of the language and culture [15] .Under the enlightenment of the postcolonial cultural theories, Sun Yifeng puts forward the concept of "the diasporic translator" who stays in the third cultural state between "foreignization" and "domestication" [16]. In the cultural studies in the light of post-colonialism, "diaspora" is a kind of existing state of culture, and "hybridity" is the nature of this state. "Hybridity" refers to the polymerization of the heterogeneous cultural elements of different cultures. Therefore, it is different from the hybridity in translation studies which is a kind of strategy for translation. Hybridity in translation is the reflection of the diasporic translator's cultural mission. Therefore, if we try to apply this concept to 
the universal translation studies, the rich meaning of hybridity as an important concept of postcolonial cultural studies may get lost [17].

\section{HYBRIDITY AS A STRATEGY FOR LITERARY TRANSLATION}

In the light of cultural globalization, there are more and more cultural communications between Chinese and Western cultures, in which translation is playing an increasingly important role. Nowadays, although the colonial system has collapsed, its influence still exists. In addition, the cultural hegemony in the worldwide is also a huge barrier for the equal and natural communication between different languages and cultures. In the field of translation studies, there also exists a tough question: how to avoid the cultural hegemony? Homi Bhabha's hybridity theory offers a good answer to this question.

Hybridity is the process and result of compromise and fusion when different language cultures contact. In the process of translation, a translator tries to put SL/SC into TL/TC and two languages and cultures collide and mix. The translated text, i.e. the hybrid text, is the product of the mixture. The hybrid text absorbs the features of two languages and cultures and represents incomparable advantages over both the SL/SC and TL/TC.

Hybridity will happen so long as there is communication between different language cultures. In this sense, all translated texts are characterized with the features hybridity, and the difference is in the degree of hybridity, which is connected with the translation strategies and methods that the translator adopts. Han Ziman ever points out that "if the translator mainly adopts the strategy of domestication, the translated text will achieve lower degree of hybridity; on the contrary, if the translator adopts the strategy of foreignization, the translated text will achieve higher degree of hybridity [14]."Some people may be confused for the difference between hybridity and foreignization, and some people even take them as the same thing. However, hybridity is not the same as the traditional foreignization as a translation method and it is more similar to the concept of "foreignization" in Venuti's "resistance translation". The theory of Venuti's foreignization strategy aims to resist cultural hegemony, ethnocentrism and cultural narcissism, so as to promote the equal communication between different cultures. "Foreignization" is such a translation strategy that will introduce the heterogeneous elements to the TT/TC [8]. As above mentioned, the translation method of "foreignization" in traditional sense is just one of methods in Venuti's "foreignizing translation", but this one is relatively commonly used. Therefore, the "foreignization translation method" in the traditional sense is supposed to be taken as the principal way to achieve "hybridity" and as main embodiment of "hybridity" in the TT [18].

\section{CONCLUSION}

For many years, there have been hot debates between literal and free translation, foreignization and domestication. But actually, according to some scholars, like Bhabha, there is no absolute literal translation or free translation; likewise, there is no absolute foreignization and domestication, because all the translation is the mixture of foreignization and domestication, i.e., all translated texts are hybrid texts, and the difference is the degree of hybridity in a certain translation. Due to the defects of pure foreignization and domestication, hybridity is naturally feasible. However, the degree of hybridity in translation is not easy to control, because it is influenced by many factors, such as the translator's subjectivity, types of source text, readers, social cultural factors and other factors. Therefore, to what degree should the translation be kept and how to keep an appropriate degree of hybridity in translation become key issues for translation scholars to concentrate on.

In the future studies, hybridity theory should be further investigated in breadth and depth. As for the literature translation, scholars are supposed to pay attention to application of hybridity theory rather than just focus on the discussion of foreignization and domestication. Only in this way can we broaden the research category of translation studies and cultural studies. The famous scholar Lv Jun also points out that the entire post-colonial criticism is under the guidance of deconstructionist theory, which is prone to lead translation studies to lose concern about the ontology of translation and focus on the external factors beyond language[19]. Therefore, for the research of literature translation, only hybridity theory is not sufficient, and "there needs to be other methods and approaches as its supplements" $[18]$.

\section{REFERENCES}

[1] Han Ziman, 2002, Hybridity and Literary Translation [[J]. Chinese Translators Journal, 2002 (2) : pp 54-58.

[2] Bhabha, H.K, The Location of Culture, London: Routledge, 1994.

[3] Anonymity.2003. Cambridge Advanced Learners Dictionary[Z]. Cambridge University Press.

[4] Robinson, D. 1997. Translation and Empire: Postcolonial Theories Explained [M]. Manchester: St Jerome.

[5] Hermans, T.1995 "Translation as Institution" [A], in Snell-Hornby, Mary et al (eds.)Translation as Intercultural Communication: Selected Paper from the EST Congress-Prague 1995[C]. Amsterdam/ Philadelphia: John Benjamins Publishing Company.

[6] Duff, A.1981.The Third Lcusguage: Recurrent Problems of Translation into English: it ain't what you do, it's the way you do it [M]. Oxford/New York/Frankfutt: Pergamon Press.

[7] Schaffner, C. \& Adab, B.1995. Translation as Intercultural Communication: Contact as Conflict [A]. In Translation as intercultural communication: selected papers from the EST Congress, Prague [C]. Philadelphia: John Benjamin's Publishing Co.

[8] Venuti, L. 1995/2004. The Translator's Invisibility-A History of Translation[M]. London: Routledge.

[9] Munday, J. 2001. Introducing Translation Studies: theories and application [M]. London and New York: Routledge.

[10] Niranjana, T. 1992. Siting Translation: History, poststructuralism, and the colonial context [M]. Berkeley, CA: University of California Press.

[11] Li Quan'an, 1997. "The hybrid Language and Tanslation", From: Lin Hantian: A Dictionary of Chinese Translation [M]. Wu Han: Hu Bei Education Press.

[12] Zheng Hailing, New Theory of Translation Criterion: Harmonious Translation Theory [J]. Chinese Translators Journal, 1999 (4): pp3-7.

[13] Yang Xiaorong, 2005, The Guidance to Translation Criticism [M]. Bei Jing: China Translation \& Publishing Corporation. 
[14] Han Ziman, 2005, Hybridity in Literary Translation [M]. Shang Hai: Shanghai Translation Publishing House.

[15] Ge Xiaoqin, 2006, A Study of Translator's Subjectivity in the Postmodernist Context [M]. Shang Hai: Shanghai Translation Publishing House.

[16] Sun Yifeng, The Cultural Misstion of the Diasporic Translators [J]. Chinese Translators Journal, 2006 (1): pp3-10.

[17] Duan Feng, 2008, Study of Literary Translation Sujectivity from the Cultural Perspective[M]. Cheng Du: Sichuan University Press.

[18] Zhang Zhiqiang. P.S. Buck's Version of Shui Hu Zhuan in the Light of the Post-colonial Translation Theory[J]. Chinese Translators Journal, 2010(2).

[19] LÜ Jun, Hou Xiangqun. Translatology-A Constructivist Perspective of Translation Study[M]. Shanghai: Shanghai Foreign Language Education Press, 2006 